\title{
Hot Deformation Behavior and Constitutive Analysis of As-Extruded Mg-6Zn-5Ca-3Ce Alloy Fabricated by Rapid Solidification
}

\author{
Chengli Bao ${ }^{1}$, Tao Zhou ${ }^{1}$, Laixin Shi ${ }^{1}{ }^{*}$, Mingao Li ${ }^{1}, \mathrm{Li} \mathrm{Hu}^{1, *} \mathbb{C}$, Mingbo Yang ${ }^{1}$ and Qiang Chen ${ }^{2}$ \\ 1 College of Material Science and Engineering, Chongqing University of Technology, Chongqing 400054, China; \\ 1770553882@2020.cqut.edu.cn (C.B.); zt19811118@cqut.edu.cn (T.Z.); limingao@cqut.edu.cn (M.L.); \\ yangmingbo@cqut.edu.cn (M.Y.) \\ 2 Southwest Technology and Engineering Research Institute, Chongqing 400039, China; \\ 2009chenqiang@hfut.edu.cn \\ * Correspondence: shilaixin2016@cqut.edu.cn (L.S.); huli@cqut.edu.cn (L.H.); \\ Tel.: +86-151-2337-6156 (L.S.); +86-173-5842-8920 (L.H.)
}

Citation: Bao, C.; Zhou, T.; Shi, L.; Li, M.; Hu, L.; Yang, M.; Chen, Q. Hot Deformation Behavior and Constitutive Analysis of As-Extruded Mg-6Zn-5Ca-3Ce Alloy Fabricated by Rapid Solidification. Metals 2021, 11, 480. https://doi.org/10.3390/ met11030480

Academic Editor: Marcello Cabibbo

Received: 27 February 2021

Accepted: 11 March 2021

Published: 14 March 2021

Publisher's Note: MDPI stays neutral with regard to jurisdictional claims in published maps and institutional affiliations.

Copyright: (c) 2021 by the authors. Licensee MDPI, Basel, Switzerland. This article is an open access article distributed under the terms and conditions of the Creative Commons Attribution (CC BY) license (https:/ / creativecommons.org/licenses/by/ $4.0 /)$.

\begin{abstract}
The plasticity of $\mathrm{Mg}-6 \mathrm{Zn}-5 \mathrm{Ca}-3 \mathrm{Ce}$ alloy fabricated by rapid solidification (RS) at room temperature is poor due to its hexagonal-close-packed (HCP) structure. Therefore, hot deformation of RS Mg-6Zn-5Ca-3Ce alloy at elevated temperature would be a major benefit for manufacturing products with complex shapes. In the present study, hot deformation behavior of as-extruded $\mathrm{Mg}-6 \mathrm{Zn}-5 \mathrm{Ca}-3 \mathrm{Ce}$ alloy fabricated by RS was investigated by an isothermal compression test at a temperature $(\mathrm{T})$ of $573-673 \mathrm{~K}$ and strain rate $(\dot{\varepsilon})$ of $0.0001-0.01 \mathrm{~s}^{-1}$. Results indicated that the flow stress increases along with the declining temperature and the rising strain rate. The flow stress behavior was then depicted by the hyperbolic sine constitutive equation where the value of activation energy $(Q)$ was calculated to be $186.3 \mathrm{~kJ} / \mathrm{mol}$. This issue is mainly attributed to the existence of fine grain and numerous second phases, such as $\mathrm{Mg}_{2} \mathrm{Ca}$ and $\mathrm{Mg}-\mathrm{Zn}-\mathrm{Ce}$ phase ( $\mathrm{T}^{\prime}$ phase), acting as barriers to restrict dislocation motion effectively. Furthermore, strain compensation was introduced to incorporate the effect of plastic strain on material constants $(\alpha, Q, n, \ln A)$ and the predicted flow stresses under various conditions were roughly consistent with the experimental results. Moreover, the processing maps based on the Murty criterion were constructed and visualized to find out the optimal deformation conditions during hot working. The preferential hot deformation windows were identified as follows: $\mathrm{T}=590-640 \mathrm{~K}, \dot{\varepsilon}=0.0001-0.0003 \mathrm{~s}^{-1}$ and $\mathrm{T}=650-670 \mathrm{~K}, \dot{\varepsilon}=0.0003-0.004 \mathrm{~s}^{-1}$ for the studied material.
\end{abstract}

Keywords: $\mathrm{Mg}-6 \mathrm{Zn}-5 \mathrm{Ca}-3 \mathrm{Ce}$ alloy; hot deformation behavior; constitutive analysis; processing map; rapid solidification

\section{Introduction}

Magnesium (Mg) alloys, which exhibit low density, high specific stiffness, high specific strength as well as good damping properties, have great potential for applications in many aspects, such as aerospace, automobile, and $3 \mathrm{C}$ industries [1-3]. Among them, $\mathrm{Mg}-\mathrm{Zn}$ (Zinc) alloys have been termed as one of the most promising alloys, as they possess superior strength, plasticity and corrosion resistance owing to the formation of metastable phase $\left(\mathrm{MgZn}_{2}\right.$ and $\left.\mathrm{Mg}_{2} \mathrm{Zn}_{3}\right)$ [4]. In recent years, alloying, known as a popular approach to improve the properties of magnesium alloys, has also been the focus of research on $\mathrm{Mg}-\mathrm{Zn}$ alloys. Ping et al. [5] reported that $\mathrm{Ca}$ (calcium) element was beneficial to the refinement of grain size and its addition would significantly improve the mechanical properties and the bio-corrosion properties of $\mathrm{Mg}-\mathrm{Zn}-\mathrm{Ca}$ alloys. Moreover, the addition of Ce (Cerium) in $\mathrm{Mg}-\mathrm{Zn}-\mathrm{Ca}$ alloys resulted in the formation of a new $\mathrm{Mg}-\mathrm{Zn}-\mathrm{Ce}$ phase ( $\mathrm{T}^{\prime}$ phase) in as-cast state, which contributes to high strength of $\mathrm{Mg}$ alloys [6,7]. Therefore, additions of $\mathrm{Ca} / \mathrm{Ce}$ 
into $\mathrm{Mg}-\mathrm{Zn}$ alloys surely possess great potential for practical applications of $\mathrm{Mg}$ alloy with enhanced mechanical properties.

Recently, rapid solidification (RS) has been treated as a superior method to refine the grain sizes and participations. Therefore, it benefits in modifying the comprehensive properties of $\mathrm{Mg}$ alloys. According to the previous study, the grain size of RS Mg-6Zn$5 \mathrm{Ca}$ alloy was refined significantly and the number of finely dispersed particles increased substantially, contributing to the compressive strength of the alloy up to $408 \mathrm{MPa}$ at ambient temperature [8]. In addition, RS improved the mechanical properties of the $\mathrm{Mg}-\mathrm{Zn}-\mathrm{Ca}-\mathrm{Ce}$ alloys at elevated temperatures due to the formation of meta-stable phases, such as $\mathrm{Mg}_{2} \mathrm{Ca}$ and $\mathrm{Mg}_{12} \mathrm{Ce}$ [4]. The aforementioned merits made $\mathrm{RS} \mathrm{Mg-6Zn-5Ca-3Ce} \mathrm{alloy} \mathrm{a} \mathrm{potential}$ $\mathrm{Mg}$ alloy. However, the subsequent processing capability of RS Mg-Zn-Ca-Ce alloy is still limited due to inadequate slip systems at ambient temperature [9-11] and plentiful hardbrittle phases [4]. Fortunately, as the temperature increases, the workability of $\mathrm{Mg}$ alloys will be improved greatly owing to the activation of non-basal slip [12] and grain boundary slip [13]. Nowadays, many studies have been performed to investigate the hot deformation behavior of $\mathrm{Mg}-\mathrm{Zn}-\mathrm{X}$ alloy [14-21]. Liu et al. [17] calculated the activation energy of the casted Mg-3Zn-Ca-0.5Sr alloy $(250.44 \mathrm{~kJ} / \mathrm{mol})$ and drew the processing map with a peak power dissipation efficiency of $42 \%$, which was observed at $603-633 \mathrm{~K}$ and $0.005-0.03 \mathrm{~s}^{-1}$. Gao et al. [18] researched the stress-strain curves of the $\mathrm{Mg}-2.3 \mathrm{Zn}-0.4 \mathrm{Mn}-0.2 \mathrm{Ce}$ alloy and concluded that the alloy exhibited a typical dynamic recrystallization (DRX) behavior with a single peak stress. Ma et al. [19] studied the thermal deformation mechanism of an extruded $\mathrm{Mg}-16 \mathrm{Al}$ alloy and identified the appropriate deformation window, where the temperature range was $633-673 \mathrm{~K}$ and the strain rate range was $0.001-0.1 \mathrm{~s}^{-1}$. Wang et al. [20] reported that many fine grains were introduced by DRX around the coarse grains at $200{ }^{\circ} \mathrm{C}$ and $1 \mathrm{~s}^{-1}$, increasing the engineering strain and promoting the work hardening.

However, few research works have been conducted previously with respect to flow behavior and workability of $\mathrm{Mg}-\mathrm{Zn}-\mathrm{Ca}-\mathrm{Ce}$ alloys during hot deformation, especially for RS $\mathrm{Mg}-\mathrm{Zn}-\mathrm{Ca}-\mathrm{Ce}$ alloys, which hinders their engineering application. Thus, understanding the hot deformation behavior and formulating some appropriate hot working conditions of RS Mg-Zn-Ca-Ce alloys are of great importance. In the present study, the true strainstress curves of RS Mg-Zn-Ca-Ce alloy were firstly obtained by thermal compression experiments. Afterwards, constitutive equations and processing maps were calculated and constructed to investigate the deformation behavior and to identify the optimal processing window of the studied material.

\section{Material and Methods}

The $\mathrm{Mg}$ alloy with a composition of $\mathrm{Mg}-6 \mathrm{Zn}-5 \mathrm{Ca}-3 \mathrm{Ce}$ was produced by RS using pure $(99.9 \%)$ magnesium, calcium, zinc, and cerium, and its chemical composition is shown in Table 1 . The as-received RS flakes were hot pressed at $573 \mathrm{~K}$ in an Ar (Argon) atmosphere. Then, the hot-pressed billets were extruded in a YJ32-315A four-column hydraulic press (Jiangdong Machinery Co., Ltd., Chongqing, China) through a cylindrical die of $50 \mathrm{~mm}$ inner diameter at an extrusion speed of $0.1 \mathrm{~mm} / \mathrm{min}$, temperature of $653 \mathrm{~K}$, and an extrusion ratio of 39:1.

Table 1. Nominal chemical composition of RS Mg-6Zn-5Ca-3Ce alloy.

\begin{tabular}{ccccc}
\hline Alloy & Zn (wt\%) & Ca (wt\%) & Ce (wt\%) & Mg \\
\hline $\mathrm{Mg}-6 \mathrm{Zn}-5 \mathrm{Ca}-3 \mathrm{Ce}$ & 6 & 5 & 3 & Balance \\
\hline
\end{tabular}

The compressive specimens were machined with a diameter of $7 \mathrm{~mm}$ and a height of $10.5 \mathrm{~mm}$ along the extrusion direction. The process of thermal hot compression and the dimensions of specimen were schematically illustrated in Figure 1. Uniaxial compression tests were conducted at the temperature of $573 \mathrm{~K}, 623 \mathrm{~K}$ and $673 \mathrm{~K}$ as well as the strain rates of $0.0001 \mathrm{~s}^{-1}, 0.001 \mathrm{~s}^{-1}$ and $0.01 \mathrm{~s}^{-1}$ on the Gleeble-1500 thermo-mechanical simulator (Data Science International, INC, St. Paul, MN, USA). Graphite lubricant was applied 
on surfaces between the specimen and press parts to guarantee good friction condition. All specimens were then deformed to the total true strain of 0.7. Before compression, the specimens were heated to deformation temperatures at a heating rate of $5 \mathrm{~K} / \mathrm{s}$ and then held for $300 \mathrm{~s}$ in order to obtain a stable and uniform temperature. In addition, for an easier understanding, the physical quantities and abbreviations encountered in this study are listed in Table 2.
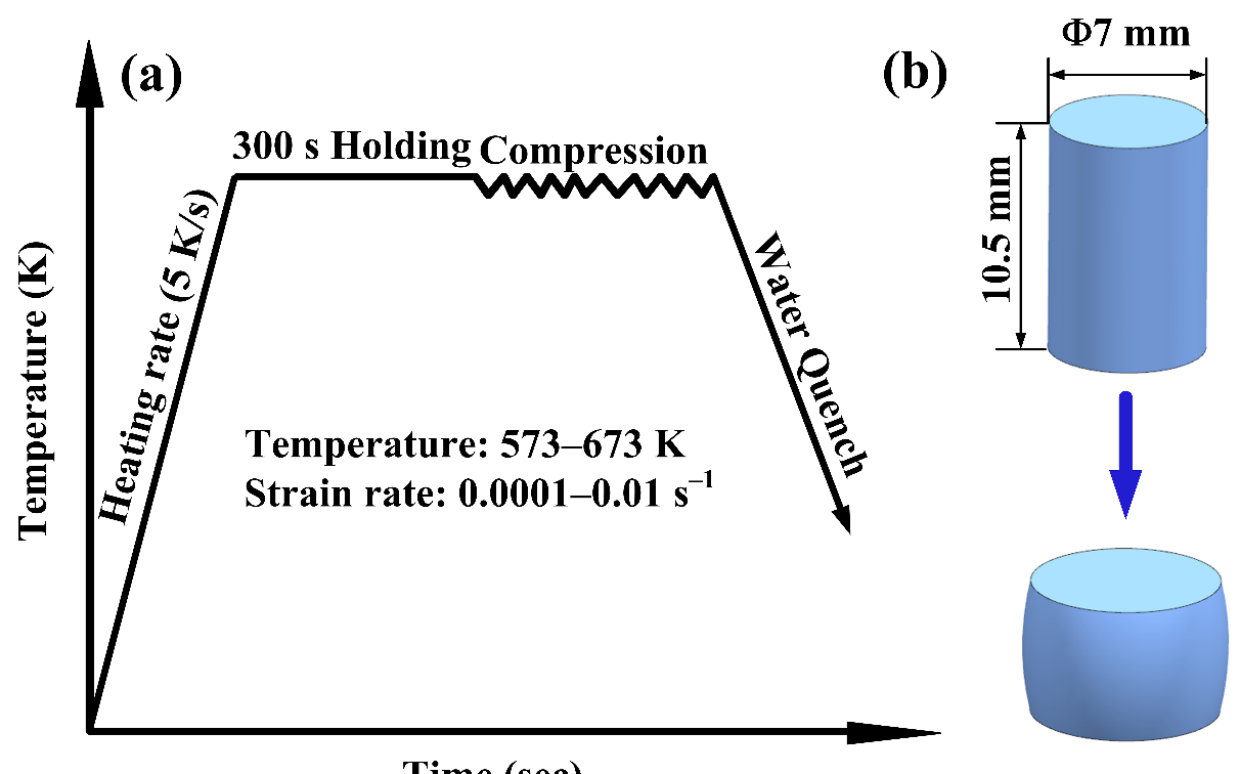

Figure 1. Schematic diagram of (a) hot compression process and (b) the dimensions of specimens.

Table 2. Nomenclatures of the physical quantities and abbreviations.

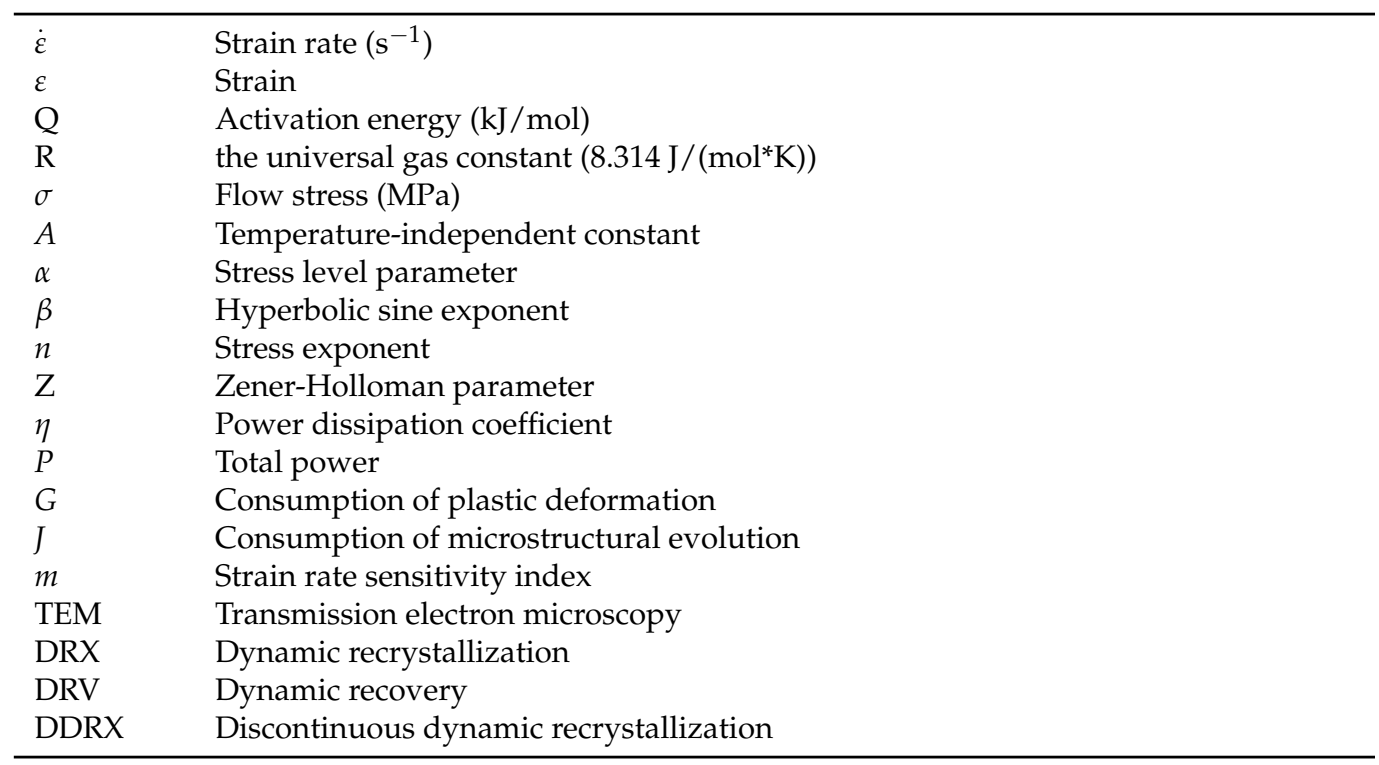

Microstructure characterization of the deformed specimens was conducted by transmission electron microscopy (TEM, Tecnai G220, FEI Company, Hillsboro, OR, USA) operated at $200 \mathrm{kV}$. The specimens for TEM observation were twin-jet electropolished using a solution of $11.6 \mathrm{~g}$ magnesium perchlorate, $5.3 \mathrm{~g}$ lithium chloride, $500 \mathrm{~mL}$ methanol and $100 \mathrm{~mL}$ 2-butoxyethanol, at $-55^{\circ} \mathrm{C}$ and $85 \mathrm{~V}$, followed by ion milling. The TEM micrographs of as-extruded $\mathrm{Mg}-6 \mathrm{Zn}-5 \mathrm{Ca}-3 \mathrm{Ce}$ alloy fabricated by RS were shown in Figure 2 . It is clear that after hot extrusion, the grain size was refined into the range of 350-1000 nm (compared with RS Mg-6Zn-5Ca-3Ce alloy [4]), which can be estimated directly from the 
TEM micrographs. Moreover, a host of particles with various sizes were distributed at the grain boundary and in the grain interior. Furthermore, the morphology of particles is quite different from each other, including spherical, elliptic and block particles. It was reported that these particles were $\mathrm{Mg}_{2} \mathrm{Ca}$ and $\mathrm{Mg}-\mathrm{Zn}-\mathrm{Ce}$ phase ( $\mathrm{T}^{\prime}$ phase) [22].
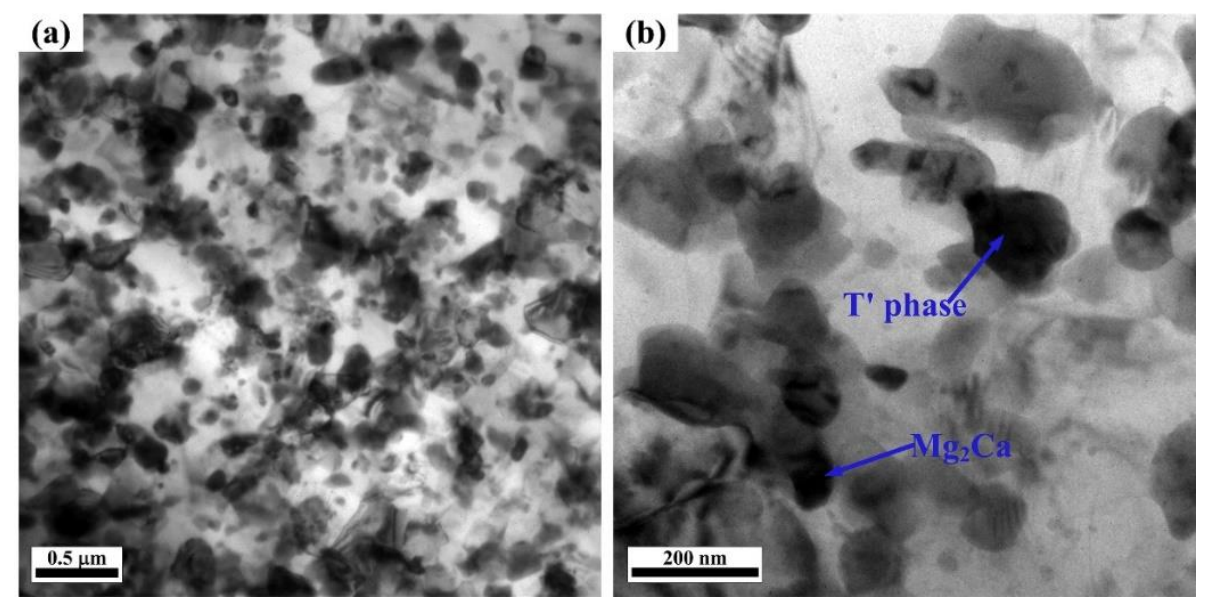

Figure 2. Transmission electron microscope (TEM) images of as-extruded $\mathrm{Mg}-6 \mathrm{Zn}-5 \mathrm{Ca}-3 \mathrm{Ce}$ alloy fabricated by RS: (a) bright image with low magnification; (b) bright image with high magnification.

\section{Results and Discussion}

\subsection{Flow Stress Behavior}

The true stress-strain curves for as-extruded $\mathrm{Mg}-6 \mathrm{Zn}-5 \mathrm{Ca}-3 \mathrm{Ce}$ alloy fabricated by $\mathrm{RS}$ at different deformation temperatures ranging from $573 \mathrm{~K}$ to $673 \mathrm{~K}$ and different strain rates varying from $0.0001 \mathrm{~s}^{-1}$ to $0.01 \mathrm{~s}^{-1}$ are shown in Figure 3. Evidently, the flow stress exhibits an increasing tendency with increasing strain rate and decreasing temperature, especially at a low temperature (Figure 3d). Moreover, the peak stress appears under an extremely low strain (even less than 0.05), indicating that the significant work-hardening effect appears at the initial deformation stage. Furthermore, the peak stress at a low temperature is higher than that of high temperature at a certain strain rate since it has more severe strain hardening in a low temperature. At the initial stage of plastic deformation, flow stress rises rapidly but does not reach the peak stress due to working hardening introduced by dislocation multiplication, pileup and tangle [23,24]. Afterwards, it increases to the peak stress slightly indicating a steady state which is a dynamic competition process between work hardening and softening by the dynamic recovery (DRV) and DRX. After that, some serrations in the stress-strain curve are observed due to the discontinuous dynamic recrystallization (DDRX) [25]. It is worth noting that when the strain rate is $0.0001 \mathrm{~s}^{-1}$, an evident decreasing trend occurs at a high temperature (623 K and $\left.673 \mathrm{~K}\right)$, implying that dynamic softening dominates the mechanical response after reaching the peak value.

\subsection{Constitutive Analysis Based on Arrhenius Equation}

In order to predict the hot workability behavior of metallic materials, different constitutive models have been constructed in order to describe the relationship between the deformation parameters. Among them, the Arrhenius constitutive model has been termed as the prevailing one due to its straightforward format and high prediction accuracy [26]. The key equation for this model would be depicted by the hyperbolic sine equation:

$$
\dot{\varepsilon}=A[\sinh (\alpha \sigma)]^{n} \exp (-Q / R T)
$$



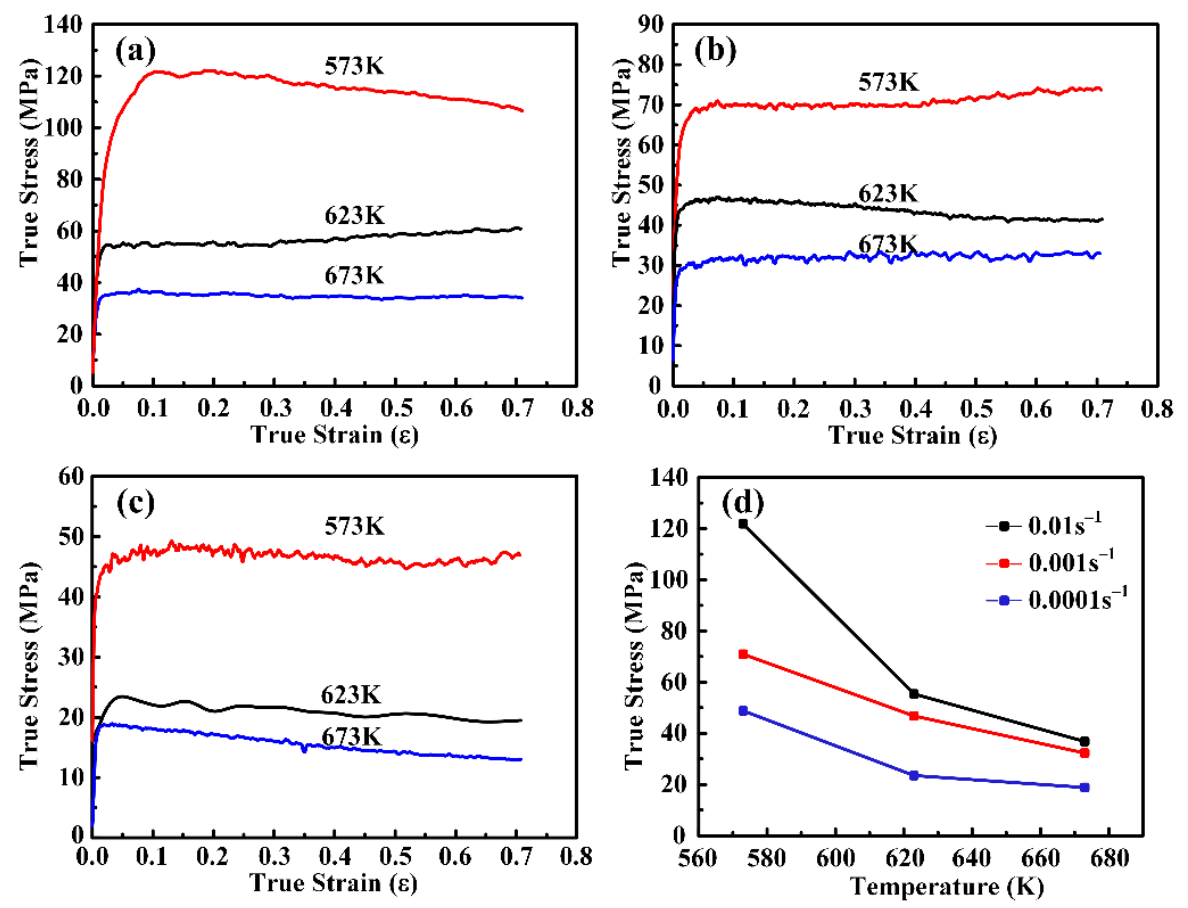

Figure 3. True stress-strain curves of as-extruded $\mathrm{Mg}-6 \mathrm{Zn}-5 \mathrm{Ca}-3 \mathrm{Ce}$ alloy fabricated by rapid solidification (RS) at (a) $0.01 \mathrm{~s}^{-1}$; (b) $0.001 \mathrm{~s}^{-1}$; (c) $0.0001 \mathrm{~s}^{-1}$ and (d) variation of the peak stress under different deformation conditions.

For the low stress level $(\alpha \sigma<0.8)$, the value of $\sinh (\alpha \sigma)$ is similar to its argument $\alpha \sigma$; While for the high stress level $(\alpha \sigma>1.2)$, the value of $\sinh (\alpha \sigma)$ is similar to the $\exp (\beta \sigma) / 2$. Thus Equation (1) can be converted into the following equations:

$$
\begin{gathered}
\dot{\varepsilon}=A_{1}(\alpha \sigma)^{n_{1}} \exp (-Q / R T)(\alpha \sigma<0.8) \\
\dot{\varepsilon}=A_{2} \exp (\beta \sigma) \exp (-Q / R T)(\alpha \sigma>1.2)
\end{gathered}
$$

where $\dot{\varepsilon}$ is strain rate $\left(\mathrm{s}^{-1}\right), R$ is the universal gas constant $\left(8.314 \mathrm{~J} /\left(\mathrm{mol}^{*} \mathrm{~K}\right)\right), Q$ is the deformation activation energy, $T$ is the absolute temperature $(\mathrm{K}), \sigma$ is the peak stress $(\mathrm{MPa})$, and $A, A_{1}, A_{2}, \alpha\left(\alpha=\beta / \mathrm{n}_{1}\right), \beta$ and $n$ are material constants $[27,28]$.

To simplify the equations, natural logarithms are introduced into both sides of Equations (1)-(3), which conform to the following equations:

$$
\begin{gathered}
\ln \dot{\varepsilon}=\ln A+n \ln [\sinh (\alpha \sigma)]-Q / R T \\
\ln \dot{\varepsilon}=\ln A_{1}+n_{1} \ln \sigma-Q / R T \\
\ln \dot{\varepsilon}=\ln A_{2}+\beta \sigma-Q / R T
\end{gathered}
$$

In accordance with Equations (5) and (6), $\ln \dot{\varepsilon}$ is linearly related to $\ln \sigma$ and $\sigma$, respectively. Thus, the average slope of $\ln \dot{\varepsilon}-\ln \sigma$ and $\ln \dot{\varepsilon}-\sigma, \mathrm{n} 1$ and $\beta$, can be achieved, where $n_{1}=5.26, \beta=0.1435$. Afterwards, $\alpha(\alpha=\beta / \mathrm{n} 1)$, can be calculated as 0.0273 . The relationships of $\ln \dot{\varepsilon}-\ln \sigma$ and $\ln \dot{\varepsilon}-\sigma$ are depicted in Figure $4 \mathrm{a}, \mathrm{b}$ ). 

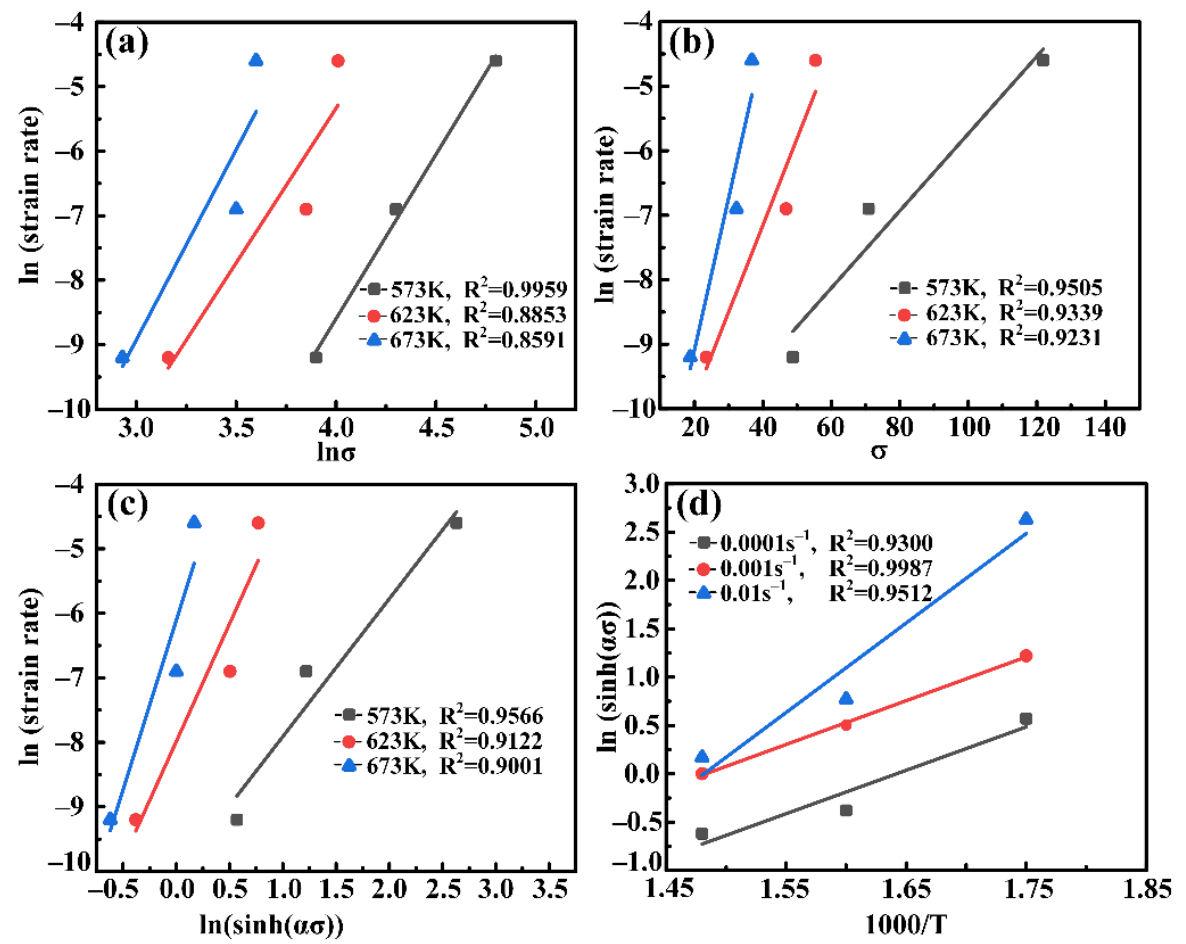

Figure 4. The linearly fitting relationship of as-extruded $\mathrm{Mg}-6 \mathrm{Zn}-5 \mathrm{Ca}-3 \mathrm{Ce}$ alloy fabricated by RS: (a) $\ln \dot{\varepsilon}-\ln \sigma ;(\mathbf{b}) \ln \dot{\varepsilon}-\sigma ;(\mathbf{c}) \ln \dot{\varepsilon}-\ln [\sinh (\alpha \sigma)]$ and (d) $\ln [\sinh (\alpha \sigma)]-\frac{1000}{T}$.

Because there are three variations in Equation (4), by calculating partial differential for temperature and strain rate, respectively, the linear relationship of $\ln [\sinh (\alpha \sigma)]-\frac{1000}{T}$ and $\ln \dot{\varepsilon}-\ln [\sinh (\alpha \sigma)]$ are drawn in Figure $4 \mathrm{c}, \mathrm{d}$. Therefore, the activation energy $Q$ can be obtained:

$$
Q=R\left[\frac{\partial \ln \dot{\varepsilon}}{\partial \ln (\sinh (\alpha \sigma))}\right]_{T}\left[\frac{\partial \ln (\sinh (\alpha \sigma))}{\partial(1000 / T)}\right]_{\dot{\varepsilon}}
$$

In the above equation, $\left[\frac{\partial \ln \dot{\varepsilon}}{\partial \ln (\sinh (\alpha \sigma))}\right]_{T}$ is the slop of $\ln \dot{\varepsilon}-\ln [\sinh (\alpha \sigma)]$ and $\left[\frac{\partial \ln (\sinh (\alpha \sigma))}{\partial(1000 / T)}\right]_{\dot{\varepsilon}}$ is that of $\ln [\sinh (\alpha \sigma)]-\frac{1000}{T}$. It can be calculated that the mean slope of $\ln [\sinh (\alpha \sigma)]-\frac{1000}{T}$ is 6.09 and that of $\ln \dot{\varepsilon}-\ln [\sinh (\alpha \sigma)]$ is 3.68. Accordingly, the current activation energy, $Q$, is estimated to be $186.3 \mathrm{~kJ} / \mathrm{mol}$, which is higher than that of the self-diffusion in pure $\mathrm{Mg}$. Zheng et al. [29] researched the effect of the addition of $\mathrm{MgO}$ on the plastic deformation behavior of $\mathrm{Mg}$ alloy and indicated that the lower activation energy $(150.3 \mathrm{~kJ} / \mathrm{mol})$ can be attribute to the fine grains and second phases. In this study, the moderate $Q$ value can be attributed to the exceptional fine grain size and the occurrence of numerous second phases, such as $\mathrm{Mg}_{2} \mathrm{Ca}$ and $\mathrm{Mg}-\mathrm{Zn}-\mathrm{Ce}$ phases ( $\mathrm{T}^{\prime}$ phase). These precipitations with good thermal stability could act as barriers to restrict dislocation motion effectively [2].

For the purpose of reflecting the influence of deformation temperature and strain rate, the Zener-Holloman parameter $(Z)$ will be introduced. Combined with the hyperbolic sine function (Equation (1)), the Z parameter is shown in Equation (8).

$$
\mathrm{Z}=\dot{\varepsilon} \exp (Q / R T)=A[\sinh (\alpha \sigma)]^{n}
$$

The relationship of $\ln [\sinh (\alpha \sigma)]$ and $\ln Z$ can be illustrated in Figure 5. Based on linear fitting, the intercept $(\ln A)$ can be obtained and subsequently the $A$ can be calculated as $8.8 \times 10^{11}$. Ultimately, the $\sigma$ can be calculated by the following equation:

$$
\sigma=\frac{1}{\alpha} \ln \left\{(Z / A)^{1 / n}+\left[(Z / A)^{2 / n}+1\right]^{1 / 2}\right\}
$$




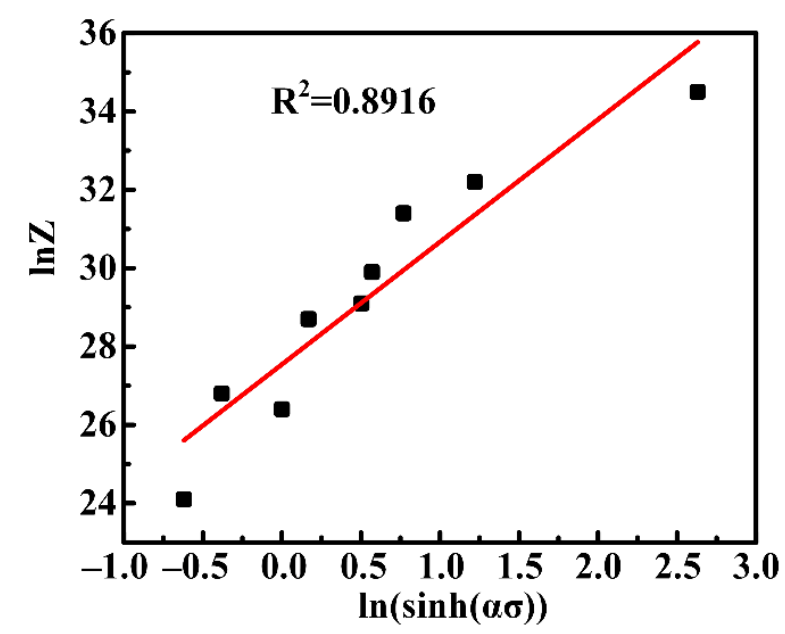

Figure 5. Relationship between the Zenner-Hollomon parameter $(\ln Z)$ and $\ln [\sinh (\alpha \sigma)]$.

Substitute the calculated value, $\alpha, Q, n$ and $A$ into Equation (1), and the constitutive equation for hot compression of as-extruded $\mathrm{Mg}-6 \mathrm{Zn}-5 \mathrm{Ca}-3 \mathrm{Ce}$ fabricated by the RS alloy can be calculated as:

$$
\dot{\varepsilon}=8.8 \times 10^{11}[\sinh (0.0273 \sigma)]^{3.13} \exp \left(-\frac{186300}{8.314 T}\right)
$$

However, intensive research has demonstrated that plastic strain significantly influences material constants within the entire strain range [30,31]. In order to predict the hot deformation behavior and flow stress more accurately, the material constants $(\alpha, Q, n$ and $\ln A$ ) in various strains at an interval of 0.05 are calculated via the coded Matlab program. The corresponding calculated results are shown in Table 3. Clearly, there indeed exists an obvious difference in strain varying from 0.05 to 0.7 . Thus, it is necessary to take the strain effect into account.

Table 3. Calculated material constants $(\alpha, Q, n$ and $\ln A)$ of as-extruded Mg-6Zn-5Ca-3Ce alloy fabricated by RS.

\begin{tabular}{ccccc}
\hline $\begin{array}{c}\text { Material } \\
\text { Constant }\end{array}$ & $\boldsymbol{\alpha}$ & $\boldsymbol{Q}(\mathrm{J} / \mathbf{m o l})$ & $\boldsymbol{n}$ & $\boldsymbol{l n} \boldsymbol{A}$ \\
\hline$\varepsilon$ & & $\dot{\varepsilon}=A[\sinh (\alpha \sigma)]^{n} \exp (-Q / R T)$ & \\
0.05 & 0.0277 & 188,910 & 3.9056 & 27.9870 \\
0.1 & 0.0278 & 187,360 & 3.5316 & 27.7654 \\
0.15 & 0.0278 & 190,060 & 3.5626 & 28.2665 \\
0.2 & 0.0281 & 180,540 & 3.3224 & 26.5097 \\
0.25 & 0.0278 & 180,420 & 3.3674 & 26.5022 \\
0.3 & 0.0281 & 177,710 & 3.2620 & 26.0034 \\
0.35 & 0.0279 & 171,520 & 3.1663 & 24.8966 \\
0.4 & 0.0278 & 165,520 & 3.1060 & 23.7974 \\
0.45 & 0.0279 & 164,540 & 3.0390 & 23.6428 \\
0.5 & 0.0280 & 168,580 & 3.0782 & 24.3824 \\
0.55 & 0.0278 & 163,070 & 3.0099 & 23.3730 \\
0.6 & 0.0276 & 160,340 & 2.9864 & 22.8882 \\
0.65 & 0.0275 & 157,600 & 2.9442 & 22.4021 \\
0.7 & 0.0272 & 159,140 & 2.9786 & 22.7239 \\
\hline
\end{tabular}

According to the principle of regression analysis, the relationship between the material constants and $\varepsilon$ could be depicted by polynomial fitting. In the present study, a sixth order polynomial is applied and the containing terms are shown in Table 4 as well as the specific constitutive equations of as-extruded $\mathrm{Mg}-6 \mathrm{Zn}-5 \mathrm{Ca}-3 \mathrm{Ce}$ alloy fabricated by RS. Moreover, the regression curves of material constants are presented in Figure 6. 
Table 4. The relationship between material constants and $\varepsilon$ using sixth degree polynomial.

\begin{tabular}{cc}
\hline Material & Mg-6Zn-5Ca-3Ce \\
\hline constant & $\begin{array}{c}Z=\dot{\varepsilon} \exp (Q / R T) \\
\end{array}$ \\
$\alpha$ & $0.02797-0.0111 \varepsilon+0.15334 \varepsilon^{2}-0.79727 \varepsilon^{3}+1.95385 \varepsilon^{4}-2.27157 \varepsilon^{5}+1.0031 \varepsilon^{6}$ \\
$Q$ & $197.3-315.3 \varepsilon+3979.9 \varepsilon^{2}-23050.1 \varepsilon^{3}+60675.7 \varepsilon^{4}-73992.7 \varepsilon^{5}+34052.1 \varepsilon^{6}$ \\
$n$ & $4.75-25.59 \varepsilon+209.6 \varepsilon^{2}-887.1 \varepsilon^{3}+1939.8 \varepsilon^{4}-2097.3 \varepsilon^{5}+887.6 \varepsilon^{6}$ \\
$\ln A$ & $29.3-51.9 \varepsilon+679.6 \varepsilon^{2}-4024.6 \varepsilon^{3}+10717.1 \varepsilon^{4}-13164.3 \varepsilon^{5}+6090.1 \varepsilon^{6}$ \\
\hline
\end{tabular}
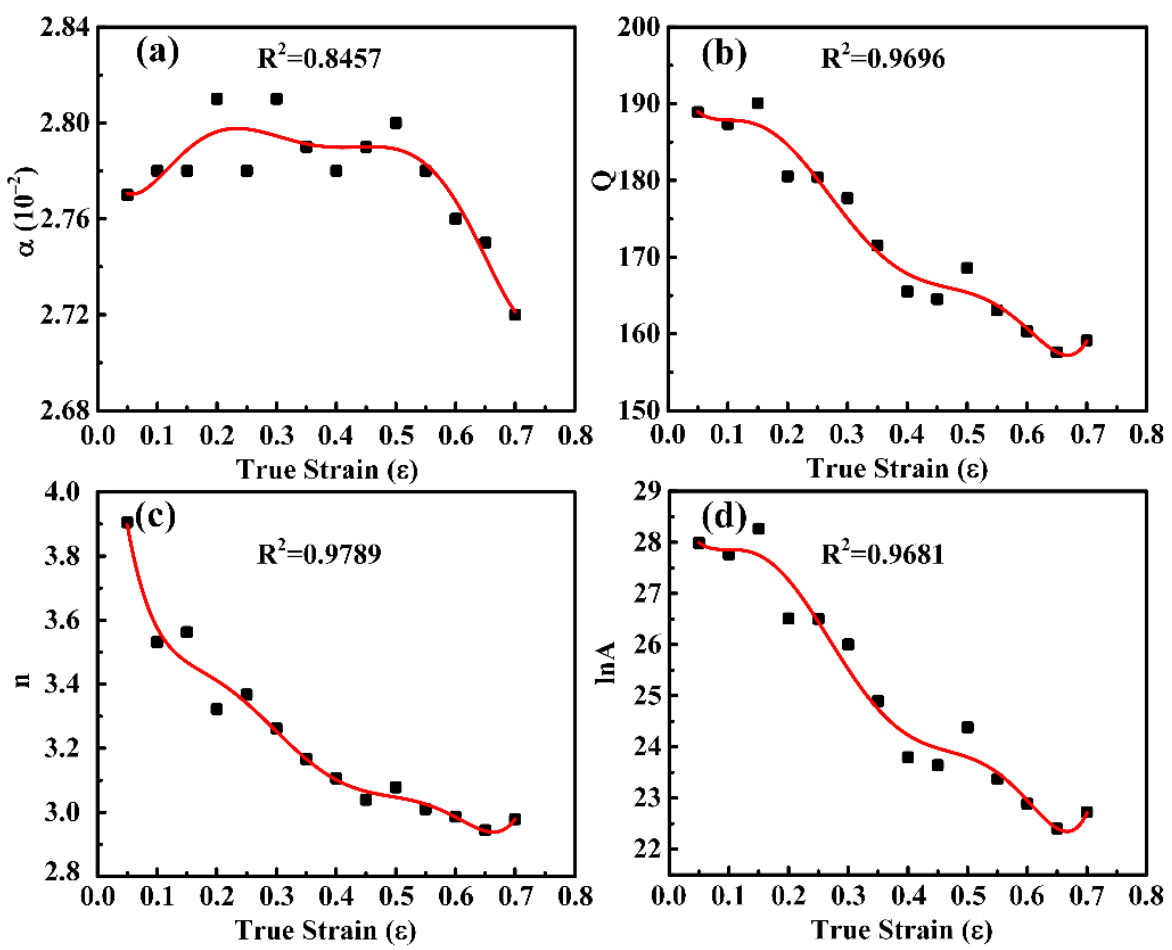

Figure 6. The polynomial fitting results of the material constants: (a) $\alpha-\varepsilon$; (b) $Q-\varepsilon$; (c) $n-\varepsilon$ and (d) $\ln A-\varepsilon$.

Based on material constants under different strains in Tables 3 and 4, the flow stress at a specific deformation condition can be calculated using Equation (10) and the calculated stress-strain curves of as-extruded $\mathrm{Mg}-6 \mathrm{Zn}-5 \mathrm{Ca}-3 \mathrm{Ce}$ alloy fabricated by RS can be obtained, as shown in Figure 7. These calculated flow stresses under various deformation conditions globally agree with the correspondingly experimental results. 

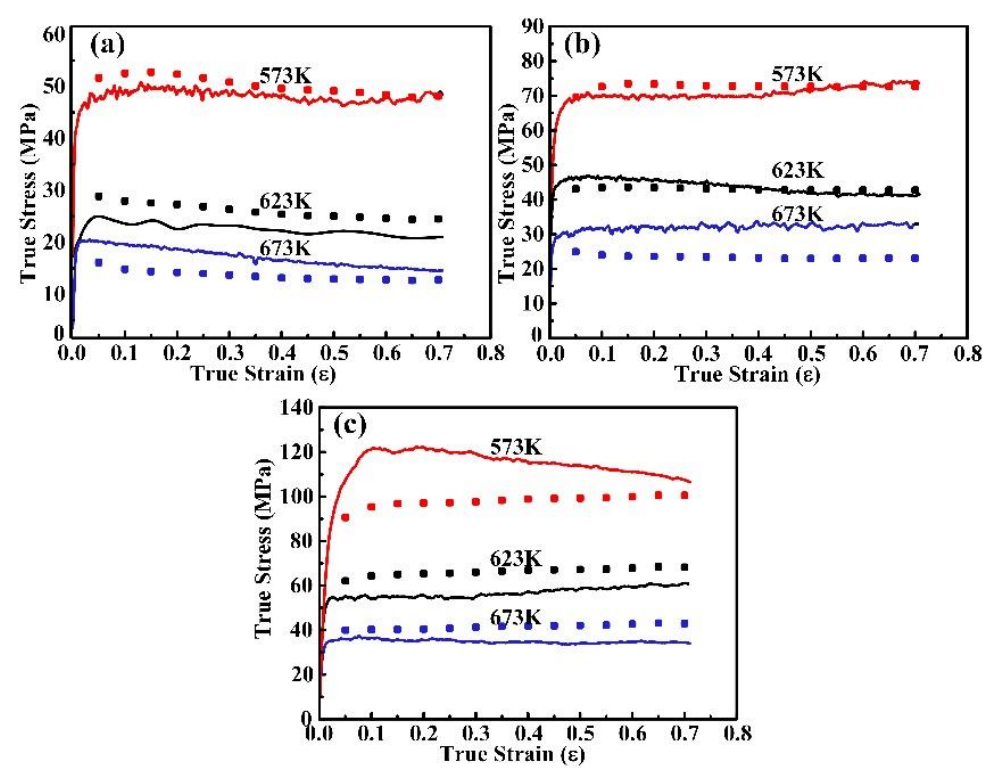

Figure 7. Measured and calculated flow stresses of as-extruded $\mathrm{Mg}-6 \mathrm{Zn}-5 \mathrm{Ca}-3 \mathrm{Ce}$ alloy fabricated by RS under various deformation conditions: (a) $0.0001 \mathrm{~s}^{-1}$; (b) $0.001 \mathrm{~s}^{-1}$ and (c) $0.01 \mathrm{~s}^{-1}$.

\subsection{Processing Maps}

The power dissipation map is usually applied to describe the microstructure evolution during the hot deformation. The thermal deformation material is considered as a nonlinear energy dissipation unit in the dynamic material model (DMM) [12,16,32]. During hot deformation, the total power $\mathrm{P}$ is converted into the $\mathrm{G}$ content and J co-content, where $\mathrm{G}$ is dissipation energy consumed by plastic deformation and $\mathrm{J}$ is consumed by microstructure evolution Thus, the total power $P$ can be expressed as:

$$
P=\sigma \dot{\varepsilon}=G+J=\int_{0}^{\dot{\varepsilon}} \sigma d \dot{\varepsilon}+\int_{0}^{\sigma} \dot{\varepsilon} d \sigma
$$

The relationship among flow stress $\sigma$, the strain rate stress $\dot{\varepsilon}$ and the dynamic constitutive equation under a given temperature can be depicted as:

$$
\sigma=K \dot{\varepsilon}^{m}
$$

where $m$ represents the strain rate sensitivity index and $K$ is the material constant. Moreover, $m$ is the proportion of dissipative power between $G$ and $J$, which is defined as:

$$
m=\frac{d J}{d G}=\left[\frac{\partial(\ln \sigma)}{\partial(\ln \dot{\varepsilon})}\right]_{\dot{\varepsilon}, T}
$$

Supposing that the material is an ideal linear dissipation body, $J$ obtains to the maximum as $m=1$ (that is ideally plastic flow):

$$
J_{\max }=\frac{1}{2} \sigma \dot{\varepsilon}
$$

As for a complicated alloy system, the relationship between flow stress and strain rate will be more consistent with the Murty criterion which is widely applicable to various $\sigma-\dot{\varepsilon}$ versus. Thus, the $G$ content can be written as:

$$
G=\int_{0}^{\dot{\varepsilon}} \sigma d \dot{\varepsilon}=\int_{0}^{\dot{\varepsilon}_{\min }} \sigma d \dot{\varepsilon}+\int_{\dot{\varepsilon}_{\min }}^{\dot{\varepsilon}} \sigma d \dot{\varepsilon}=\left(\frac{\sigma \dot{\varepsilon}}{m+1}\right)_{\dot{\varepsilon}=\dot{\varepsilon}_{\min }}+\int_{\dot{\varepsilon}_{\min }}^{\dot{\varepsilon}} \sigma d \dot{\varepsilon}
$$


where $\dot{\varepsilon}_{\text {min }}$ means the minimum strain rate during hot deformation.

The power dissipation coefficient, $\eta$, is defined as $J / J$ max which is a dimensionless parameter to access the power dissipation. Thus, $\eta$ can be expressed as:

$$
\eta=\frac{J}{J_{\max }}=\frac{P-G}{J_{\max }}=2\left(1-\frac{1}{\sigma \dot{\varepsilon}} \int_{0}^{\dot{\varepsilon}} \sigma d \dot{\varepsilon}\right)=2\left[1-\left(\left[\frac{\sigma \dot{\varepsilon}}{m+1}\right]_{\dot{\varepsilon}=\dot{\varepsilon}_{\min }}+\int_{\dot{\varepsilon}_{\min }}^{\dot{\varepsilon}} \sigma \mathrm{d} \dot{\varepsilon}\right) / \sigma \dot{\varepsilon}\right]
$$

On account of the maximum principles of irreversible thermodynamics, an instability criterion was constructed by Murty et al. to predict the sprout of flow instability as follows [32-34]:

$$
2 m<\eta
$$

The unstable flow caused by the adiabatic shear will occur when all power is converted into viscoplastic heat $(J=0)$, which means $\eta=0$. Thus, only when the domains locate in $0<\eta<2 m$ and $0<m \leq 1$, will the stable material flow with DRX or DRV appear.

Finally, the power dissipation maps were established and the processing maps could be constructed by superimposing the power dissipation maps and instable maps using Matlab 2020 and Origin 8.0, as shown in Figures 8 and 9. The values on counter lines symbolize the power dissipation efficiency $(\eta)$ which can describe the microstructure evolution during hot deformation [35]. The shaded areas highlighted by red color mean the unstable regions while the areas in blue represent stable areas. It is clear that lower power dissipation efficiency lies in regions with lower temperature and higher strain rate, which exhibits the typically unstable flow. In the case of a relatively low temperature, DRX can hardly happen, and thus extensive dislocations are inevitably accumulated with increasing plastic deformation, causing severe working hardening [36]. Therefore, this condition trends to induce unstable flow of metallic materials. Moreover, it is too fast for a sufficient DRX to occur at a high strain rate, which contributes to dislocation multiplication, pile-ups and tangle. Consequently, this condition is also unfavorable for the hot working of metallic materials. Thus, choosing appropriate hot deformation conditions is a perquisite for ensuring that sufficient DRX occurs in the material and it possesses enough power dissipation efficiency. For the studied material, there exist two optimal deformation domains, which are the domain $\mathrm{I}\left(\mathrm{T}=590-640 \mathrm{~K}, \dot{\varepsilon}=0.0001-0.0003 \mathrm{~s}^{-1}\right)$ and domain II $\left(\mathrm{T}=650-670 \mathrm{~K}, \dot{\varepsilon}=0.0003-0.004 \mathrm{~s}^{-1}\right)$, as shown in Figure 9. The power dissipation efficiency of these two domains is relatively large, where DRX would take place more completely.
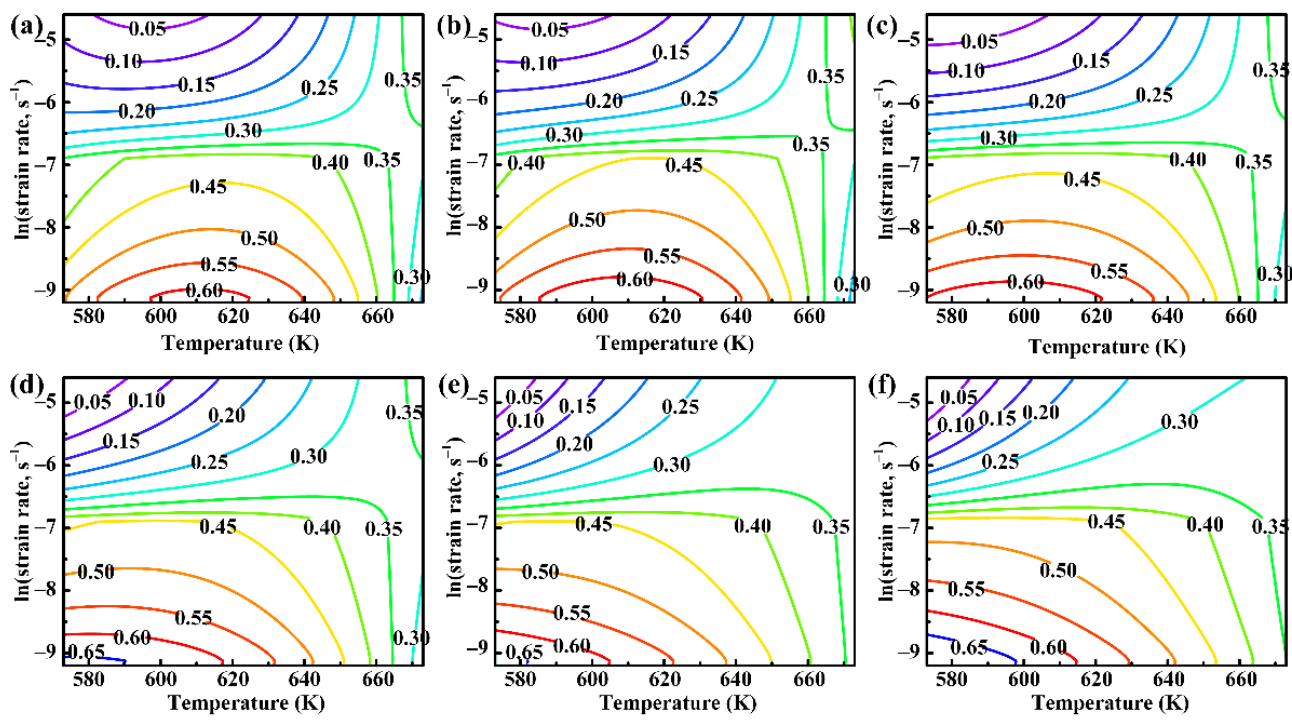

Figure 8. The power dissipation maps of as-extruded $\mathrm{Mg}-6 \mathrm{Zn}-5 \mathrm{Ca}-3 \mathrm{Ce}$ fabricated by RS at various strains: (a) 0.1 ; (b) 0.2 ; (c) 0.3 ; (d) 0.4 ; (e) $0.5 ;$ (f) 0.6 . 

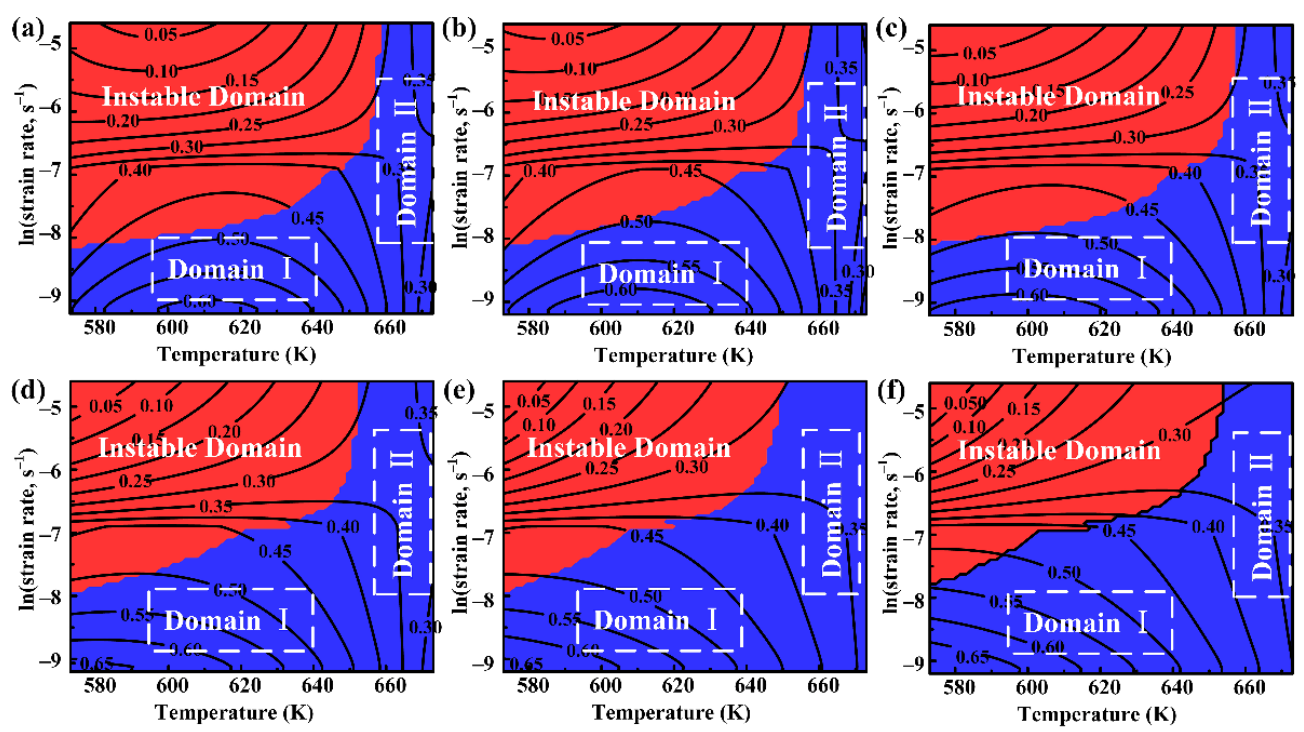

Figure 9. The processing maps of as-extruded $\mathrm{Mg}-6 \mathrm{Zn}-5 \mathrm{Ca}-3 \mathrm{Ce}$ fabricated by RS at various strains: (a) $0.1 ;$ (b) 0.2 ; (c) $0.3 ;$ (d) $0.4 ;$ (e) $0.5 ;$ (f) 0.6 .

\section{Conclusions}

The present study focused on the hot deformation behavior of as-extruded Mg- $6 \mathrm{Zn}$ 5Ca-3Ce alloy fabricated by RS via isothermal compression tests at different temperatures and strain rates. Based on true stress-strain curves, the constitutive equations, power dissipation maps and processing maps using Murty criteria were established and the optimal deformation parameters were identified. Finally, the preferable process conditions were identified. The conclusions are as follows:

1. During isothermal compression, the flow stress of the alloy increases significantly with the increasing strain rate and the declining temperature.

2. The Arrhenius constitutive equation of the studied material can be described as $\dot{\varepsilon}=8.8 \times 10^{11}[\sinh (0.0273 \sigma)]^{3.13} \exp \left(-\frac{186300}{8.314 T}\right)$. Strain compensation is considered to introduce the effect of plastic strain on material parameters. The calculated flow stresses at various deformation conditions are generally consistent with the experimental results.

3. The dissipation maps and processing maps of as-extruded $\mathrm{Mg}-6 \mathrm{Zn}-5 \mathrm{Ca}-3 \mathrm{Ce}$ alloy fabricated by RS in the temperature range of 573-673 K and the strain rate range of $0.0001-0.01 \mathrm{~s}^{-1}$ were constructed. The preferential processing domains can be identified, which lie in the domain I $\left(\mathrm{T}=590-640 \mathrm{~K}, \dot{\varepsilon}=0.0001-0.0003 \mathrm{~s}^{-1}\right)$ and domain II $\left(\mathrm{T}=650-670 \mathrm{~K}, \dot{\varepsilon}=0.0003-0.004 \mathrm{~s}^{-1}\right)$.

Author Contributions: Conceptualization, methodology, visualization and writing—original draft preparation, C.B.; data curation and software, T.Z.; validation and writing-review and editing, L.S., L.H.; formal analysis, M.L.; supervision, M.Y. and Q.C. All authors have read and agreed to the published version of the manuscript.

Funding: This work was supported by the National Natural Science Foundation of China (Grant Nos. 51805064, 51701034, 51822509), the Scientific and Technological Research Program of Chongqing Municipal Education Commission (Grant No. KJQN201801137), the Basic and Advanced Research Project of Chongqing Science and Technology Commission (Grant Nos. cstc2017jcyjAX0062, cstc2018jcyjAX0035), the Chongqing University Key Laboratory of Micro/Nano Materials Engineering and Technology (Grant No. KFJJ2003).

Institutional Review Board Statement: Not applicable.

Informed Consent Statement: Not applicable. 
Data Availability Statement: The data presented in this study are available on request from the corresponding author. The data are not publicly available due to privacy.

Conflicts of Interest: The authors declare no conflict of interest.

\section{References}

1. He, J.J.; Mao, Y.; Fu, Y.J.; Jiang, B.; Xiong, K.; Zhang, S.M.; Pan, F.S. Improving the room-temperature formability of Mg-3Al-1Zn alloy sheet by introducing an orthogonal four-peak texture. J. Alloys Compd. 2019, 797, 443-455. [CrossRef]

2. Li, K.; Chen, Z.Y.; Chen, T.; Shao, J.B.; Wang, R.K.; Liu, C.M. Hot deformation and dynamic recrystallization behaviors of Mg-Gd-Zn alloy with LPSO phases. J. Alloys Compd. 2019, 792, 894-906. [CrossRef]

3. Shao, J.B.; Chen, Z.Y.; Chen, T.; Wang, R.K.; Liu, Y.L.; Liu, C.M. Texture evolution, deformation mechanism and mechanical properties of the hot rolled Mg-Gd-Y-Zn-Zr alloy containing LPSO phase. Mater. Sci. Eng. A 2018, 731, 479-486. [CrossRef]

4. Zhou, T.; Chen, D.; Chen, Z.H.; Chen, J.H. Investigation on microstructures and properties of rapidly solidified Mg-6wt.\% Zn-5wt.\% Ca-3wt.\% Ce alloy. J. Alloys Compd. 2009, 475, L1-L4. [CrossRef]

5. Yin, P.; Li, N.F.; Lei, T.; Liu, L.; Ouyang, C. Effects of Ca on microstructure, mechanical and corrosion properties and biocompatibility of Mg-Zn-Ca alloys. J. Mater. Sci. Mater. M 2013, 24, 1365-1373. [CrossRef]

6. Du, Y.Z.; Zheng, M.Y.; Qiao, X.G.; Wu, K.; Liu, X.D.; Wang, G.J.; Lv, X.Y. Microstructure and mechanical properties of Mg-Zn-CaCe alloy processed by semi-continuous casting. Mater. Sci. Eng. A 2013, 582, 134-139. [CrossRef]

7. Du, Y.Z.; Liu, D.J.; Ge, Y.F. Effects of Ce addition on mechanical and corrosion properties of the as-extruded Mg-Zn-Ca Alloy. J. Mater. Eng. Perform. 2020, 30, 488-496. [CrossRef]

8. Zhou, T.; Yang, M.B.; Zhou, Z.M.; Hu, J.J.; Chen, Z.H. Microstructure and mechanical properties of rapidly solidified/powder metallurgy Mg-6Zn and Mg-6Zn-5Ca at room and elevated temperatures. J. Alloys Compd. 2013, 560, 161-166. [CrossRef]

9. You, J.; Huang, Y.J.; Liu, C.M.; Zhan, H.Y.; Huang, L.X.; Zeng, G. Microstructural study of a Mg-Zn-Zr alloy hot compressed at a high strain rate. Materials 2020, 13, 2348. [CrossRef]

10. Kang, Q.; Jiang, H.T.; Kuai, Z.; Zhang, Y.; Wang, Y.J.; Cai, Z.X. Optimization of the hot compression constitutive equation and processing map of $\mathrm{Mg}-4 \mathrm{Zn}-0.8 \mathrm{Ca}$ (wt\%) alloy. Mater. Res. Express 2019, 6, 086526-086543. [CrossRef]

11. Papillon, J.; Salero, P.; Mercier, F.; Fabrègue, D.; Maire, É. Compressive deformation behavior of dendritic Mg-Ca(-Zn) alloys at high temperature. Mater. Sci. Eng. A 2019, 763, 138180-138187. [CrossRef]

12. Zhang, Z.M.; Yan, Z.M.; Du, Y.; Zhang, G.S.; Zhu, J.X.; Ren, L.Y.; Wang, Y.D. Hot deformation behavior of homogenized Mg-13.5Gd-3.2Y-2.3Zn-0.5Zr alloy via hot compression tests. Materials 2018, 11, 2282. [CrossRef]

13. Koike, J.; Ohyama, R.; Kobayashi, T.; Suzuki, M.; Maruyama, K. Grain-boundary sliding in AZ31 magnesium alloys at room temperature to 523K. Mater. Trans. 2003, 44, 445-451. [CrossRef]

14. Zhang, H.X.; Chen, S.F.; Cheng, M.; Zheng, C.; Zhang, S.H. Modeling the dynamic recrystallization of Mg-11Gd-4Y-2Zn-0.4Zr alloy considering non-uniform deformation and LPSO kinking during hot compression. Acta Metall. Sin. Engl. Lett. 2019, 32, 1122-1134. [CrossRef]

15. Alizadeh, R.; Mahmudi, R.; Ruano, O.A.; Ngan, A.H.W. Constitutive analysis and hot deformation behavior of fine-grained Mg-Gd-Y-Zr alloys. Metall. Mater. Trans. A 2017, 48, 5699-5709. [CrossRef]

16. Li, B.; Teng, B.G.; Xu, W.C. Hot deformation characterization of homogenized Mg-Gd-Y-Zn-Zr alloy during isothermal compression. JOM 2019, 71, 4059-4070. [CrossRef]

17. Liu, H.N.; Li, Y.J.; Zhang, K.; Li, X.G.; Ma, M.L.; Shi, G.L.; Yuan, J.W.; Wang, K.K. Microstructure, hot deformation behavior, and textural evolution of $\mathrm{Mg}-3 \mathrm{wt} \% \mathrm{Zn}-1 \mathrm{wt} \% \mathrm{Ca}-0.5 \mathrm{wt} \% \mathrm{Sr}$ Alloy. J. Mater. Sci. 2020, 55, 12434-12447. [CrossRef]

18. Lei, G.; Luo, A.A. Hot deformation behavior of as-cast Mg-Zn-Mn-Ce alloy in compression. Mater. Sci. Eng. A 2013, 560, 492-499.

19. Ma, Z.W.; Hu, F.Y.; Wang, Z.J.; Fu, K.J.; Wei, Z.X.; Wang, J.J.; Li, W.J. Constitutive equation and hot processing map of Mg-16Al magnesium alloy bars. Materials 2020, 13, 3107. [CrossRef] [PubMed]

20. Wang, J.H.; Li, S.P.; Ma, H.B. Evolution of microstructure, texture, and mechanical properties of as-extruded ND/ZK60 composite during hot compression deformation. Metals 2020, 10, 1191. [CrossRef]

21. Li, M.A.; Xiao, S.L.; Xu, L.J.; Chen, Y.Y.; Tian, J.; Zhang, B.Y. Mechanical properties, deformation behavior and microstructure evolution of Ti-43Al-6Nb-1Mo-1Cr alloys. Mater. Charact. 2017, 136, 69-83. [CrossRef]

22. Zhou, T.; Song, D.H.; Chen, Z.H. Microstructures, Mechanical and creep properties of rapidly solidification/powder metallurgy Mg-6wt.\%Zn alloys with 5wt.\%Ce and 1.5wt.\%Ca additions. Mater. Sci. Forum 2016, 861, 253-263. [CrossRef]

23. Shao, Z.W.; Zhu, X.R.; Wang, R.; Wang, J.; Xu, Y.D.; Zhao, B.R.; Ling, G.P. Hot deformation and processing map of as-homogenized Mg-9Gd-3Y-2Zn-0.5Zr alloy. Mater. Des. 2013, 51, 826-832. [CrossRef]

24. Xu, C.; Pan, J.P.; Nakata, T.; Qiao, X.G.; Chi, Y.Q.; Zheng, M.Y.; Kamado, S. Hot compression deformation behavior of Mg-9Gd2.9Y-1.9Zn-0.4Zr-0.2Ca (wt\%) alloy. Mater. Charact. 2017, 124, 40-49. [CrossRef]

25. Xue, Y.; Zhang, Z.M.; Lu, G.; Xie, Z.P.; Yang, Y.B.; Cui, Y. Study on flow stress model and processing map of homogenized Mg-Gd-Y-Zn-Zr alloy during thermomechanical processes. J. Mater. Eng. Perform. 2014, 24, 964-971. [CrossRef]

26. Zhang, C.S.; Ding, J.; Dong, Y.Y.; Zhao, G.Q.; Gao, A.J.; Wang, L.J. Identification of friction coefficients and strain-compensated Arrhenius-type constitutive model by a two-stage inverse analysis technique. Int. J. Mech. Sci. 2015, 98, 195-204. [CrossRef]

27. Zhou, H.; Wang, Q.D.; Ye, B.; Guo, W. Hot deformation and processing maps of as-extruded Mg-9.8Gd-2.7Y-0.4Zr Mg alloy. Mater. Sci. Eng. A 2013, 576, 101-107. [CrossRef] 
28. Chen, B.; Zhou, W.M.; Li, S.; Li, X.L.; Lu, C. Hot compression deformation behavior and processing maps of Mg-Gd-Y-Zr alloy. J. Mater. Eng. Perform. 2013, 22, 2458-2466. [CrossRef]

29. Zheng, H.R.; Yu, L.T.; Lyu, S.Y.; You, C.; Chen, M.F. Insight into the role and mechanism of nano MgO on the hot compressive deformation behavior of Mg-Zn-Ca alloys. Metals 2020, 10, 1357. [CrossRef]

30. Lin, Y.C.; Xia, Y.C.; Chen, X.M.; Chen, M.S. Constitutive descriptions for hot compressed 2124-T851 aluminum alloy over a wide range of temperature and strain rate. Comput. Mater. Sci. 2010, 50, 227-233. [CrossRef]

31. Wang, Y.J.; Peng, J.; Zhong, L.P.; Pan, F.S. Modeling and application of constitutive model considering the compensation of strain during hot deformation. J. Alloys Compd. 2016, 681, 455-470. [CrossRef]

32. Xu, W.C.; Jin, X.Z.; Shan, D.B.; Chai, B.X. Study on the effect of solution treatment on hot deformation behavior and workability of Mg-7Gd-5Y-0.6Zn-0.8Zr magnesium alloy. J. Alloys Compd. 2017, 720, 309-323. [CrossRef]

33. Murty, S.V.S.N.; Rao, B.N. Instability map for hot working of 6061 Al-10 vol\% metal matrix composite. J. Phys. D Appl. Phys. 1998, 31, 3306-3311. [CrossRef]

34. Murty, S.V.S.N.; Rao, B.N. On the development of instability criteria during hot working with reference to IN 718. Mater. Sci. Eng. A 1998, 254, 76-82. [CrossRef]

35. Xia, X.S.; Chen, Q.; Li, J.P.; Shu, D.Y.; Hu, C.K.; Huang, S.H.; Zhao, Z.D. Characterization of hot deformation behavior of as-extruded Mg-Gd-Y-Zn-Zr alloy. J. Alloys Compd. 2014, 610, 203-211. [CrossRef]

36. Ullmann, M.; Kittner, K.; Prahl, U. Hot deformation and dynamic recrystallisation behaviour of twin-roll cast Mg-6.8Y-2.5Zn-0.4Zr magnesium alloy. Materials 2021, 14, 307. [CrossRef] [PubMed] 